\title{
EDITORIAL LA ENSEÑANZA DEL PASADO. EDUCACIÓN FRENTE ADOCTRINAMIENTO
}

\begin{abstract}
¿Qué une al pueblo? ¿Las huestes? ¿El oro? ¿Las banderas...? Las historias. No hay nada más poderoso en el mundo que una buena historia; nadie puede detenerla, ningún enemigo puede vencerla [...] Nuestro pasado. ¿Quién mejor para conducirnos al futuro?
\end{abstract}

(Juego de Tronos, temporada 8, episodio 6).

Lo que une al pueblo, por encima del dinero o de los ejércitos -decía Tyrion Lannister en el desenlace televisivo de Juego de Tronos-, son las historias; de ahí la importancia de controlar la narración de los hechos sucedidos. Ya decía el slogan orwelliano del Partido de 1984, «el que controla el pasado (...) controla también el futuro. El que controla el presente, controla el pasado». El control sobre el pasado ha sido siempre una de las principales herramientas del poder. Ya en los mitos griegos la conexión entre poder-memoria-historia aparece ilustrada mediante la unión de Zeus con la titánide Mnemósine -la memoria-, de quienes desciende precisamente Clío -la musa de la historia-. La vinculación entre historia y poder se estrechó más claramente si cabe con la aparición de los sistemas educativos en Occidente. Estos sistemas educativos buscaban, en su origen, preparar mano de obra -en relación con las revoluciones industriales- y formar ciudadanos de los nuevos estados-nación -en relación con las revoluciones ilustradas-. Ambas líneas mantienen en cierto modo su influencia en la actual enseñanza del pasado.

Por un lado, la consideración de la preparación de mano de obra como principal meta de los sistemas educativos, lo que podríamos denominar la visión mercantilista de la educación, conlleva el desgaste de aquellas disciplinas que, con mayor o menor criterio, se supone que no aportan lo suficiente a la empleabilidad de los discentes. El objetivo, desde esta perspectiva utilitarista, sería la instrucción de trabajadores y consumidores 0 , podríamos matizar más, empleados no problemáticos 
y clientes acríticos. En este contexto puede entenderse la calamitosa degradación de la formación artística y humanística, bien visible por la progresiva desaparición del latín y el griego de los planes educativos o por la insuficiente importancia dada a disciplinas como la música o la filosofía. Sin arte, música, filosofía, literatura... la comprensión del pasado -así como del presente- solo puede ser incompleta y sesgada. No es tampoco una novedad; ya en España, durante el franquismo, el ministro José Solís Ruiz, al que se conociese cómo «la sonrisa del régimen», pronunció en las Cortes, durante la discusión sobre los planes de educación, aquella célebre frase «más deporte y menos latín»; Adolfo Muñoz Alonso contestó certeramente a la pregunta de para qué servía la enseñanza de esa lengua muerta: «Por de pronto, señor ministro, para que a Su Señoría, que ha nacido en Cabra, le llamen egabrense y no otra cosa».

Por otro lado, la necesidad de formar ciudadanos hacía -y sigue haciendofundamental la enseñanza del pasado. De un tipo concreto de pasado. Para que los súbditos de las monarquías se convirtiesen en ciudadanos de los nuevos estadosnación era necesario un proceso de legitimación de esta nueva realidad política, siendo la enseñanza de la historia una herramienta imprescindible para la creación de las nuevas identidades $-y$ alteridades-. Los historiadores, ya profesionalizados, construirán nuevos relatos sobre la historia de los estados-nación, que será la que con el tiempo se enseñará fundamentalmente en las escuelas. Se legitimaban de este modo las nuevas formas políticas, nuevas relaciones de poder -y de dependencia-. Sin un tipo de historia particular difícilmente hubiese sido posible construir este tipo de identidades nacionales. $Y$ no solo se construyeron, sino que se les otorgó un cierto carácter esencial, casi atemporal. Aunque pueda parecer una paradoja, la propia creación de los relatos sobre los estados-nación hizo pasar a las naciones como algo no construido, algo que ha existido desde tiempos casi inmemoriales; visión que en cierto modo aún pervive. Así, se puede hablar de la Historia de España en la Edad Antigua, como si hubiese existido una identidad española en el mundo antiguo. Incluso se puede hablar sin pudor alguno de la Prehistoria en Castilla y León -o en cualquier otra entidad territorial administrativa actual sin sentido en los tiempos pretéritos-. Orwell, en su distopía mencionada -1984-, mostraba cómo el Partido, mediante sus mecanismos de control ideológico, había conseguido que se aceptase que «lo que ahora era verdad, había sido verdad eternamente y lo seguiría siendo", que se aceptase que el pasado, alterable por su misma naturaleza, nunca hubiese sido alterado. En cierto modo, algo similar podría aplicarse a ciertas enseñanzas de las historias nacionales y regionales.

A través de la escuela, siguiendo los planes educativos marcados desde el poder, se enseñó a los niños que eran ciudadanos de un país, un país con un pasado glorioso, con símbolos compartidos por todos, con grandes héroes y hazañas dignas de ser recordadas. El pasado era presentado como algo lineal, objetivo, inequívoco y centrado, no solo en el propio territorio del estado, sino en aspectos concretos de 
este, en la élite política, es decir, fundamentalmente en los varones poderosos. La «historia universal» enseñada era la historia de los grupos dominantes de Occidente, una historia por supuesto etnocéntrica, androcéntrica y colonialista.

Este objetivo de los sistemas educativos -la formación de ciudadanos- sigue teniendo su repercusión y, aunque las relaciones se han globalizado, la enseñanza del pasado en las escuelas sigue primando la transmisión de las identidades nacionales, así como de nuevas identidades de los territorios administrativos recientemente creados a los que se hace necesario otorgar una cierta legitimidad histórica. El patrimonio es entendido como una valoración de lo local, más que de lo universal y con un mayor peso de lo material que de lo inmaterial -salvo quizás en ciertos aspectos que permiten reforzar la identidad local-. Aunque no faltan discursos favorables hacia la interculturalidad, en Occidente poca presencia tiene en los planes educativos África -la cuna de la humanidad-, Asia -tan relevante para cualquier visión global de la historia universal- u Oceanía -sin apenas presencia en los libros de texto-. Esta ausencia es percibida también con claridad en las asignaturas con contenidos de historia de la literatura, de la filosofía y del arte.

Por otra parte, la formación de los ciudadanos de los estados-nación requería, junto a esta legitimación de las nuevas formas de relaciones de poder, la transmisión de los valores, normas y costumbres que debían conocer y respetar estos futuros ciudadanos. Para ello, el conocimiento del pasado constituía también una importante herramienta. Y lo sigue haciendo. Ahora bien, la perspectiva histórica permite comprender el pasado «desde» nuestro presente, pero no debe hacernos ver el pasado "como» presente. El conocimiento crítico del pasado posibilita comprender mejor el presente, desde el que interrogamos al pasado; pero el presentismo -la comparación anacrónica del pasado con el presente-supone un error básico de análisis que lleva a perder la perspectiva histórica necesaria para la comprensión tanto nuestras sociedades como de las pretéritas.

Es tan frecuente como erróneo el utilizar la primera persona al hablar de los protagonistas del pasado, produciendo una identificación pasado-presente: "las mujeres tuvimos un papel importante en las sociedades antiguas», "los cristianos reconquistamos España», "los españoles descubrimos América», etc. Esta identificación con los sujetos del pasado va unida a la proyección de nuestros propios valores, juzgando las relaciones sociales, políticas y económicas desde nuestro prisma, sin comprender el contexto histórico. La enseñanza de la historia puede corregir este planteamiento erróneo, pero también puede fomentarlo, en función de los objetivos que se planteen y de los métodos que se utilicen.

La enseñanza de la historia puede permitir dotar de legitimidad a las leyes existentes, instruyendo en la importancia de respetar acríticamente los valores constitucionales del país, pero también puede mostrar que lo legal y lo ético no tienen por qué coincidir; que la esclavitud fue legal y que hace no tanto tiempo protestar contra la segregación racial era ilegal, que Rosa Parks se negó a ceder su asiento a 
un blanco en 1955, actuando en contra de la ley en EE. UU., un país con unos sólidos principios democráticos.

La perspectiva histórica permite entender que los valores son una construcción y que cambian con el tiempo -ni siquiera una misma persona tiene la misma escala de valores a lo largo de su vida-. No son por tanto un fenómeno objetivo y compartido por todas las sociedades, ni son inmutables en el tiempo. Sabemos que nuestros valores no son los mismos que los de las generaciones anteriores, igual que sabemos que tampoco lo serán los de las generaciones venideras. Todos los sistemas han educado en valores -en los valores propios del sistema, se entiende-, del mismo modo que legitiman las relaciones de poder imperantes, mostrando sus sistemas políticos, sociales y económicos como los mejores posibles -o como los menos malos-, y justificando las desigualdades.

En los sistemas democráticos la enseñanza del pasado debe afrontar estas disonancias existentes entre el conocimiento científico del pasado y el (ab)uso de su enseñanza por parte el poder para legitimarse política, ideológica, social y económicamente.

Para lograr que la educación sea realmente intercultural, algo quizás más necesario que nunca, es imprescindible tener en cuenta no solo el conocimiento del entorno inmediato, sino también el de las sociedades más lejanas; tampoco pueden ser obviados los grupos no mayoritarios o dominantes -como pueden ser los pueblos originarios en América, los gitanos, etc.-. La ignorancia -el desconocimiento del otro- es la base del racismo, la xenofobia, el clasismo y el sexismo.

Del mismo modo, la enseñanza del pasado debe tener en cuenta a colectivos que hasta épocas recientes han estado silenciados en la historiografía, y en gran medida siguen ocupando un papel marginal en los sistemas educativos; es el caso de las mujeres, de la infancia, la vejez...

Junto a las necesarias relaciones entre lo local y lo global que debe establecer el conocimiento del pasado, debe llevarse a cabo también una superación de las limitaciones impuestas por la compartimentación y la fragmentación de las periodizaciones tradicionales. Debe entenderse -y enseñarse- que los procesos históricos no son fenómenos aislados unos de otros, y una época no puede entenderse sin las anteriores, siendo tan importante la (pre)historia más remota como la historia del tiempo presente, del mismo modo que una casa no debe carecer de tejado, ni de cimientos. Para el conocimiento del pasado es tan fundamental aprender cómo se interpretan los restos materiales de las civilizaciones ancestrales, como a entender los documentos escritos o audiovisuales más recientes, además por supuesto de saber valorar la memoria y los testimonios de quienes han vivido esta historia del tiempo presente.

Finalmente, el uso del pasado en la formación en valores debe afrontar un gran reto. Formar en valores en un sistema democrático implica -o debería implicar- formar ciudadanos con pensamiento crítico. Esto es, formar individuos 
autónomos, que utilicen el conocimiento para pensar por sí mismos, construyendo de este modo su propia escala de valores. Ningún discurso es axiológicamente neutro, pero existe una línea, no precisamente fina, que separa la educación del adoctrinamiento, de la mera manipulación ideológica. Educar supone no imponer los valores propios, sino permitir alcanzar los conocimientos necesarios para hacer sus propios juicios, para discernir, para elegir lo que se considera bueno o malo, y actuar en consecuencia -de ahí precisamente la importancia fundamental de las humanidades-. Es decir, educar implica en última instancia conducir a los individuos para que puedan llegar a pensar por sí mismos que nuestros valores pueden ser cuestionables y cuestionados, para que puedan llegar incluso a defender unos valores que nosotros consideramos problemáticos o reprobables. Para que nuevas Rosa Park no cedan su asiento en el autobús, o para que colectivos oprimidos se rebelen ante la injusticia en nuevos Stonewall. Porque formar a individuos para que asuman de forma pasiva y conformista nuestros propios valores y normas no es educar críticamente, sino utilizar la escuela como instrumento de adoctrinamiento, para crear individuos dóciles y sumisos, como sucedía en la escuela opresiva brillantemente mostrada en Pink Floyd - The Wall (1982). Las escuelas de los regímenes totalitarios, además de formar individuos «útiles» para la sociedad, también educan en valores, en los valores del régimen, al que la enseñanza del pasado, especialmente el reciente, dota de legitimidad, justificando las relaciones de poder existentes. Los estados democráticos deben estar dispuestos actuar de otra manera para ser realmente democráticos, a permitir que sus propios principios sean puestos en cuestión y a enseñar el pasado histórico de manera no idealizada.

Enfrentarse a estos desafíos supone un gran reto para los docentes. Supone en primer lugar la existencia de un diálogo continuo entre las ciencias históricas y las de la educación; porque no es posible enseñar sin conocer-primum discere, deinde docere-y porque de poco sirve investigar si los resultados no se transmiten, o si lo hacen décadas después, de manera sesgada y cuando los planteamientos han sido ya superados o matizados historiográficamente largo tiempo atrás. La historia -la historia rigurosa, se entiende- no debe quedar solo en manos de eruditos que solo debatan dentro su reducido círculo de conocimiento. Porque no se trata de defender ese círculo esotérico, reservado exclusivamente a los iniciados, sino de abrirlo para enriquecer el intercambio de ideas. No se trata de defender la importancia de unas áreas de conocimiento frente a la injerencia de otras, de resaltar la mayor relevancia de una época o de unos temas sobre otros, sino de crear unos muy necesarios espacios interdisciplinares que enriquezcan los debates y nos permitan alcanzar una necesaria visión global del pasado y del presente.

Todo ello conlleva la necesidad de una muy sólida y exigente formación por parte tanto de los docentes como de los historiadores, una formación que quizás convendría replantear. 
El objetivo no es fácil de alcanzar, pues se trata de ser capaces, como el dios Jano, de mirar tanto al pasado como al futuro. Porque conocer críticamente el pasado permite hacer frente a discursos manipuladores y adoctrinadores, permite comprender el presente desde una postura racional, conocernos mejor a nosotros y al otro, y actuar así autónoma y libremente, y no mediante la mera sumisión y obediencia a lo ya establecido. Solo así podremos actuar para construir un futuro más justo y más equitativo. Solo así podemos en definitiva tratar de acercarnos a esa anhelada utopía que se aleja cuando caminamos hacia ella -que diría Galeano-.

También al igual que el dios Jano deberíamos mirar tanto a Occidente como a Oriente. Pero ese es otro tema, al que El Futuro del Pasado dedicará su próximo monográfico.

$\begin{array}{ccc}\text { Iván Pérez Miranda } & \text { Silvia Medina Quintana } & \text { Roberto García Morís } \\ \text { Director de } & \text { Coordinadora } & \text { Coordinador } \\ \text { El Futuro del Pasado } & \text { del monográfico } & \text { del monográfico }\end{array}$

